Review article

\title{
Allotransplantation of donor rectus fascia for abdominal wall closure in transplant patients: A systematic review
}

\author{
Yveline Janssen $^{\mathrm{a}}$, Nele Van De Winkel ${ }^{\mathrm{a}, *, 1}$, Jacques Pirenne ${ }^{\mathrm{b}}$, Laurens J. Ceulemans ${ }^{\mathrm{c}}$, \\ Marc Miserez ${ }^{\text {a, } 2}$ \\ ${ }^{a}$ Department of Abdominal Surgery, University Hospitals Leuven, Belgium \\ ${ }^{\mathrm{b}}$ Leuven Intestinal Failure and Transplantation (LIFT), Department of Abdominal Transplant Surgery, Department of Microbiology, Immunology and Transplantation, \\ University Hospitals Leuven, KU, Leuven, Belgium \\ ${ }^{\mathrm{c}}$ Leuven Intestinal Failure and Transplantation (LIFT), Department of Thoracic Surgery, Department of Chronic Diseases and Metabolism, research consortium \\ BREATHE, University Hospitals Leuven, KU, Leuven, Belgium
}

\section{A R T I C L E I N F O}

\section{Keywords:}

Rectus fascia

Allotransplantation

Abdominal wall closure

Liver transplantation

Multivisceral transplantation

Intestinal transplantation

\begin{abstract}
A B S T R A C T
Background: Abdominal wall closure after intestinal, multivisceral or liver transplantation can be a major challenge. Different surgical techniques have been described to close complex abdominal wall defects, but results remain variable. Two promising transplant techniques have been developed using either non-vascularized or vascularized donor rectus fascia. This systematic review aimed to evaluate the feasibility, safety, and effectiveness of the two techniques.

Methods: A systematic review was performed in accordance with the Preferred Reporting Items for Systematic reviews and Meta-Analyses (PRISMA) guidelines. Human studies published between January 2000 and April 2020 were included. Methodological quality appraisal was done using an adapted 10-item standardized checklist.

Results: The search resulted in 9 articles including 74 patients. Both techniques proved to be feasible and had similar results. After non-vascularized rectus fascia allotransplantation, there was a slightly higher rate of surgical site infections in the earlier reports. Overall, there were few complications, no fascial graft related rejections or deaths. The included articles scored low on quality appraisal, mostly due to the small number of cases and scarcely reported outcome parameters.

Conclusions: This systematic literature review reports two emerging new techniques for complex abdominal wall closure in transplant patients, with promising results. Standardized data collection in a prospective manner could give us more detailed information about short- and long-term outcomes. Preclinical animal studies are necessary for a thorough investigation of the mechanisms of graft integration, the risk of hernia development and the alloimmune response against the graft.
\end{abstract}

\section{Introduction}

Primary closure of the abdominal wall after intestinal (ITx), liver (LTx) or multivisceral (MVTx) transplantation can be difficult to achieve due to several factors. Most of these patients have a history of multiple abdominal surgeries, ostomy, fistula(e), wound infections and may have suffered from short bowel syndrome [1-6]. This leads to the presence of a hostile and contracted abdominal wall at the time of their transplantation with subsequent loss of abdominal domain. During transplantation it is not always feasible to match donor and recipient size which further compromises the abdominal domain. In addition, transplantation itself causes edema of donor organ(s) and recipient's abdominal wall which only aggravates the size mismatch. The nonability to close the abdomen is mainly a problem in ITx and MVTx, and occurs in 20 to $85 \%$ of patients [1,3,4,6-12]. However, closing the abdominal wall is important since the presence of an open abdomen is associated with an estimated morbidity up to $50 \%$ and mortality of $10 \%$ [3]. Multiple techniques have been developed to facilitate abdominal

\footnotetext{
* Corresponding author at: Abdominale heelkunde, Herestraat 49, 3000 Leuven, Belgium.

E-mail address: Nele.vandewinkel@uzleuven.be (N. Van De Winkel).

1 Shared first authorship, contributed equally.

2 Shared senior authorship, contributed equally.
} 
wall closure in transplant patients such as the reduction of donor-organ size and/or enlargement of the recipient's abdominal domain. The latter can be achieved with the use of tissue expanders, reconstruction with mesh materials, component separation techniques, autologous tissue transfer or full thickness abdominal wall transplantation $[1,3,4,7,13-15]$. Since these surgical techniques are often complex, cause high morbidity, do not always create enough additional space and/or have variable results, transplant surgeons have sought for other options [10]. Gondolesi et al. first introduced the use of nonvascularized donor rectus fascia that was sutured as an inlay patch into the abdominal wall defect [4]. Later, Agarwal et al. presented the en-bloc transplantation of a liver with the vascularized posterior rectus fascia, attached by the falciform ligament [17]. Several additional reports by other transplant groups have been published since then. With this systematic review we want to focus on abdominal wall closure in transplant patients and critically evaluate the vascularized and nonvascularized rectus fascia allotransplantation (ATx) techniques.

\section{Materials and methods}

\subsection{Study selection}

This systematic review was performed using standard methodology and was registered in the PROSPERO database (CRD42018093923) (http://www.crd.york.ac.uk/PROSPERO/). Results were reported using the PRISMA guidelines.

Study inclusion criteria were: literature written in English, published between January 2000 and April 2020, and only human studies.

Exclusion criteria were: animal studies, review papers, editorials, opinions and biographies.

The following databases were used: Pubmed, Embase and Cochrane Library; https://clinicaltrials.gov was checked as well.

The first search was carried out on the 22nd of March 2017. Search terms were: (abdominal OR 'abdominal wall') AND (closure OR reconstruction OR transplant OR transplantation OR allotransplantation OR allograft) AND (rectus AND fascia OR 'rectus sheath') AND ('multivisceral transplantation' OR 'multiorgan transplantation' OR 'intestinal transplantation' OR 'liver transplantation' OR 'bowel transplantation'). As a second-level search, the references of the full-text articles assessed for eligibility and congress proceedings of the European Society for Organ Transplantation and the Congress of the Intestinal Rehabilitation and Transplant Association were screened for relevant articles. A second search on April 10th, 2020, complemented with independent literature searches were also carried out.

\subsection{Data extraction}

Data extraction included information on the author, year of publication, center, study design, sample size, sample characteristics (type of transplantation, type of abdominal wall closure, etc.) and reported findings such as the presence of surgical site infections (SSI), ventral hernia occurrence, abdominal closure, rejection, death (Tables 1 and 2) and reoperations (Table 3 ). Taking of biopsies without performing other actions, was not considered as a reoperation. The extracted data were reviewed by 3 researchers (Y.J., N.V. and L.J.C.).

\subsection{Methodological study quality assessment}

Eligibility assessment was carried out independently by 2 reviewers (Y.J., N.V.) disagreements were resolved by consensus. Quality assessment of the individual articles was conducted using an adapted 10-item standardized checklist (Table 4), a checklist originally published by our group for a systematic literature review [18]. The scoring and corresponding color scheme applied to each item was: no or not reported: 0 (red); partially reported: 1 (orange) and yes: 2 (green).

Table 1

Patient demographics.

\begin{tabular}{|c|c|c|c|c|c|c|c|c|c|}
\hline Center & First author & $\begin{array}{l}\text { Publication } \\
\text { year }\end{array}$ & Study type & $\begin{array}{l}\text { Transplant } \\
\text { type }\end{array}$ & $\begin{array}{l}\text { Number of } \\
\text { patients }\end{array}$ & Child or adult & Gender & SOT & $\begin{array}{l}\text { Third party } \\
\text { graft }\end{array}$ \\
\hline DO & Justo [10] & 2020 & $\begin{array}{l}\text { Case } \\
\text { report }\end{array}$ & NVRF ATx & 2 & 1 child, 1 adult & $1 \mathrm{~F}, 1 \mathrm{M}$ & 2 LTx & 1 \\
\hline $\mathrm{CU}$ & Amin [14] & 2019 & Case series & & 21 & NM & NM & $\begin{array}{l}17 \text { ITx } \\
3 \text { LTx } \\
1 \text { KTx }\end{array}$ & 3 \\
\hline KHP & Cassar [2] & 2019 & $\begin{array}{l}\text { Case } \\
\text { report }\end{array}$ & & 2 & 2 children & $1 \mathrm{~F}, 1 \mathrm{M}$ & 2 cLITx & 2 \\
\hline FF & Farinelli [3] & 2017 & Case series & & 19 & $\begin{array}{l}9 \text { children, } 10 \\
\text { adults }\end{array}$ & NM & $\begin{array}{l}12 \text { ITx } \\
3 \text { MvTx } \\
2 \text { cLITx } \\
2 \text { LTx }\end{array}$ & $\begin{array}{l}1 \\
0 \\
0 \\
0\end{array}$ \\
\hline CUB & Gerlach [1] & 2012 & Case series & & 3 & 3 adults & $\mathrm{NM}$ & 3 MvTx & NM \\
\hline $\begin{array}{l}\text { UM, MSSM, } \\
\text { FF }\end{array}$ & Gondolesi [4] & 2009 & Case series & & 16 & $\begin{array}{l}5 \text { children, } 11 \\
\text { adults }\end{array}$ & $11 \mathrm{~F}, 5 \mathrm{M}$ & $\begin{array}{l}5 \text { MvTx } \\
4 \text { ITx } \\
1 \text { cLITx } \\
4 \text { LTx } \\
2 \text { mMvTx }\end{array}$ & $\begin{array}{l}2 \\
1 \\
1 \\
4 \\
1\end{array}$ \\
\hline DU & Reddy J [5] & 2016 & Case series & VRF ATx & 6 & 6 children & NM & $\begin{array}{l}2 \operatorname{MvTx} \\
4 \text { LTx }\end{array}$ & 0 \\
\hline UCMC & Lee [15] & 2013 & Case series & & 4 & 4 children & $2 \mathrm{~F}, 2 \mathrm{M}$ & $\begin{array}{l}1 \text { mMvTx } \\
3 \text { LTx } \\
1 \text { Re-LTx }\end{array}$ & 0 \\
\hline DU & $\begin{array}{l}\text { Ravindra } \\
\text { [24] }\end{array}$ & 2011 & $\begin{array}{l}\text { Case } \\
\text { report }\end{array}$ & & 1 & 1 child & $1 \mathrm{M}$ & 1 cLITx & 0 \\
\hline
\end{tabular}

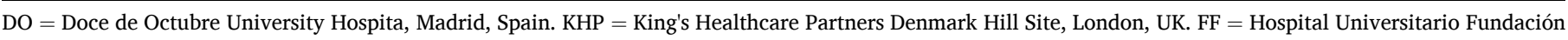

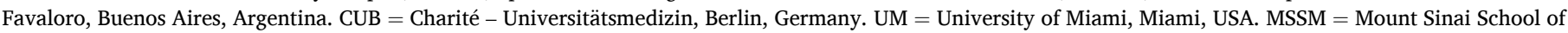

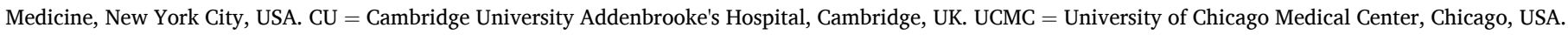

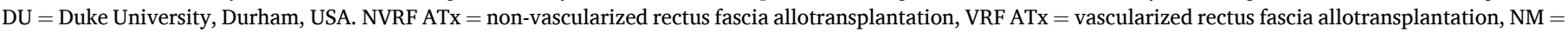

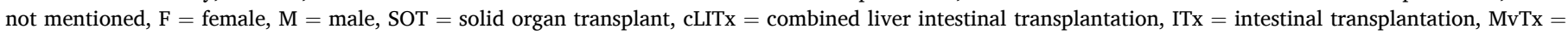

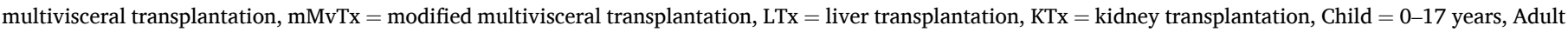
$\geq 18$ years. 
Table 2

Study outcomes.

\begin{tabular}{|c|c|c|c|c|c|c|c|c|c|c|c|c|c|c|c|}
\hline \multirow[t]{3}{*}{ First author } & \multirow{3}{*}{$\begin{array}{l}\text { Transplant } \\
\text { type }\end{array}$} & \multirow[t]{3}{*}{ SOT } & \multicolumn{9}{|c|}{ Short term outcomes } & \multicolumn{2}{|c|}{ Long term outcomes } & \multirow{2}{*}{\multicolumn{2}{|c|}{$\begin{array}{l}\text { Follow-up (months) } \\
\text { Mortality }\end{array}$}} \\
\hline & & & \multirow[t]{2}{*}{ SSI } & \multirow[t]{2}{*}{ Sepsis } & \multirow{2}{*}{$\begin{array}{l}\text { SOT } \\
\text { Rejection }\end{array}$} & \multirow{2}{*}{$\begin{array}{l}\text { Graft } \\
\text { loss }\end{array}$} & \multirow{2}{*}{$\begin{array}{l}\begin{array}{l}\text { Fascial } \\
\text { closure }\end{array} \\
\text { I }\end{array}$} & \multicolumn{4}{|c|}{ Skin closure } & \multirow{2}{*}{$\begin{array}{l}\text { Hernia } \\
\text { formation }\end{array}$} & \multirow{2}{*}{$\begin{array}{l}\text { SOT } \\
\text { rejection }\end{array}$} & & \\
\hline & & & & & & & & II & I & II & & & & & \\
\hline Justo I (10) & NVRF ATx & 2 LTx & 0 & 0 & 0 & 0 & 1 & 1 & 1 & 1 & Bogota bag & 0 & 0 & 0 & 4.0 \\
\hline \multirow{3}{*}{ Amin I (14) } & & 17 ITx & NM & 0 & NM & NM & NM & NM & 0 & NM & NM & NM & & & \\
\hline & & 3 LTx & & 0 & & & & & 0 & & & & & & \\
\hline & & $1 \mathrm{KTx}$ & & 0 & & & & & 0 & & & & & & \\
\hline Cassar N (2) & & 2 cLITx & NM & NM & NM & 0 & 0 & 2 & 0 & 2 & VAC & NM & NM & 0 & Mean 18,5 \\
\hline \multirow{4}{*}{ (3) } & & 12 ITx & 2 & NM & 0 & 2 & NM & NM & 0 & 3 & NM & $52.2+/-43.6$ & & & \\
\hline & & $3 \mathrm{MvTx}$ & 0 & & & 0 & & & & 0 & & & & & \\
\hline & & 2 cLITx & 0 & & & 0 & & & & 0 & & & & & \\
\hline & & $2 \mathrm{LTx}$ & 1 & & & 1 & & & & 0 & & & & & \\
\hline $\begin{array}{l}\text { Gerlach UA } \\
\text { (1) }\end{array}$ & & 3 MvTx & 0 & NM & NM & 0 & 3 & 0 & 0 & 3 & Polygalactin mesh, VAC, STSG & NM & NM & 0 & 12.0 \\
\hline Gondolesi G & & 5 MvTx & 3 & 1 & NM & $2^{*}$ & NM & 3 & 2 & Wet to dry & 0 & NM & 3 & Mean & \\
\hline \multirow{4}{*}{ (4) } & & 4 ITx & 0 & 1 & & & & 4 & 0 & dressings & & & 1 & 17.3 & \\
\hline & & 1 cLITx & 0 & 0 & & & & 1 & 0 & & & & 0 & & \\
\hline & & $4 \mathrm{LTx}$ & 3 & 2 & & & & 3 & 1 & & & & 2 & & \\
\hline & & $\begin{array}{l}2 \\
\text { mMvTx }\end{array}$ & 1 & 0 & & & & 2 & 0 & & & & 1 & & \\
\hline \multirow[t]{2}{*}{ Reddy J (5) } & VRF ATx & $2 \mathrm{MvTx}$ & 0 & 0 & 0 & NM & 1 & 1 & 1 & 1 & Polytetrafluoroethylene & 0 & 0 & 1 & Median \\
\hline & & 4 LTx & & & & & 1 & 3 & 0 & 4 & patch, SG & & & 0 & 12.0 \\
\hline \multirow[t]{3}{*}{ Lee JC (15) } & & $\begin{array}{l}1 \\
\text { mMvTx }\end{array}$ & 0 & 1 & 0 & 0 & 1 & 0 & 1 & 0 & VAC, Acellular dermis & 0 & 0 & 1 & Mean 3.7 \\
\hline & & 3 LTx & 1 & 0 & 0 & 1 & 1 & $2^{* * *}$ & 0 & 2 & & 0 & 0 & 0 & \\
\hline & & 1 Re-LTx & 0 & 0 & 0 & 0 & $1 * *$ & 0 & 1 & 0 & & 0 & 0 & 0 & \\
\hline $\begin{array}{l}\text { Ravindra KV } \\
\text { (24) }\end{array}$ & & 1 cLITx & NM & NM & 0 & 0 & 1 & 0 & NM & & & 0 & 0 & 0 & 6.0 \\
\hline
\end{tabular}

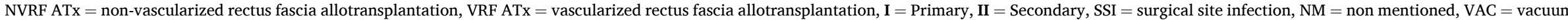

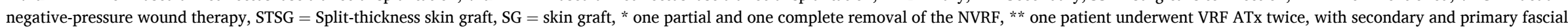
closure respectively. 
Table 3

Reoperations.

\begin{tabular}{|c|c|c|c|c|c|c|}
\hline $\begin{array}{l}\text { Transplant } \\
\text { type }\end{array}$ & First Author & SOT & $\begin{array}{l}\text { Total number of } \\
\text { reoperations }\end{array}$ & $\begin{array}{l}\text { Number of } \\
\text { patients }\end{array}$ & $\begin{array}{l}\text { Timing of } \\
\text { reoperation }\end{array}$ & Reason for reoperation \\
\hline \multirow[t]{12}{*}{ NVRF ATx } & Justo [10] & LTx & 1 & 1 & 4 months & 1 Biliary anastomotic stricture \\
\hline & Amin [14] & NM & 10 & 21 & $\mathrm{NM}$ & NM \\
\hline & Cassar [2] & cLITx & 1 & 1 & 1 year & 1 Gastrostomy insertion and ileostomy reversal \\
\hline & \multirow[t]{7}{*}{ Farinelli [3] } & ITx & 5 & 4 & \multirow[t]{5}{*}{$<1$ month } & 1 Evisceration \\
\hline & & MvTx & 10 & 3 & & 6 Abdominal collections \\
\hline & & LTx & 1 & 1 & & 5 Abdominal hematomas \\
\hline & & & & & & 1 Acute intestinal obstruction \\
\hline & & & & & & 1 Intra-abdominal bleeding \\
\hline & & ITx & 6 & 4 & \multirow[t]{2}{*}{$>1$ month } & 3 Enterectomies for rejection* \\
\hline & & cLITx & 1 & 1 & & $\begin{array}{l}3 \text { Abdominal collections } \\
1 \text { Acute intestinal obstruction }\end{array}$ \\
\hline & Gerlach [1] & MvTx & 18 & 3 & NM & NM \\
\hline & $\begin{array}{l}\text { Gondolesi } \\
\text { [4] }\end{array}$ & NM & NM & NM & NM & NM \\
\hline \multirow[t]{10}{*}{ VRF ATx } & \multirow[t]{2}{*}{ Reddy J [5] } & LTx & Range 2-4 & 4 & \multirow[t]{2}{*}{ NM } & \multirow{2}{*}{$\begin{array}{l}\text { Continuity surgery, removal of the temporary mesh and } \\
\text { definitive closure }\end{array}$} \\
\hline & & MvTx & & 1 & & \\
\hline & \multirow[t]{7}{*}{ Lee [15] } & $\operatorname{mMvTx}$ & 4 & 1 & \multirow[t]{5}{*}{$<1$ month $^{* *}$} & 4 Liver synthetic dysfunction \\
\hline & & LTx & 5 & 2 & & 2 Second look \\
\hline & & & & & & 1 Definitive closure \\
\hline & & & & & & 1 Retransplantation *** \\
\hline & & & & & & 1 Hepatic artery thrombosis \\
\hline & & LTx & 3 & 3 & $>1$ month** & 2 Definitive closure \\
\hline & & & & & & 1 Suprahepatic IVC stenosis \\
\hline & $\begin{array}{l}\text { Ravindra } \\
{[24]}\end{array}$ & cLITx & NM & NM & NM & NM \\
\hline
\end{tabular}

$\mathrm{NM}=$ not mentioned, IVC $=$ inferior vena cava, $* 1$ acute rejection, 2 chronic rejections, $* *$ approximate timing, $* * *$ SOT and VRF.

Table 4

Quality assessment.

\begin{tabular}{|c|c|c|c|c|c|c|c|c|c|c|}
\hline $\begin{array}{l}\text { Num } \\
\text { ber }\end{array}$ & Appraisal question & 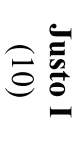 & 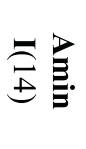 & 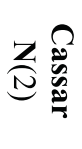 & 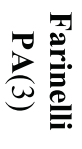 & 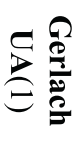 & 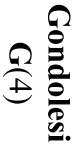 & 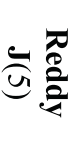 & 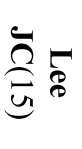 & 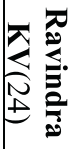 \\
\hline 1 & $\begin{array}{c}\text { Definition of surgical } \\
\text { technique }\end{array}$ & 0 & 2 & 2 & 2 & 1 & 2 & 2 & 2 & 1 \\
\hline 2 & Prospective design & 0 & 0 & 0 & 0 & 0 & 0 & 0 & 0 & 0 \\
\hline 3 & $\begin{array}{l}\text { Description of time } \\
\text { period }\end{array}$ & 1 & 0 & 1 & 2 & 2 & 2 & 1 & 2 & 1 \\
\hline 4 & $\begin{array}{c}\text { Description of } \\
\text { sampling design }\end{array}$ & 0 & 0 & 0 & 2 & 2 & 0 & 2 & 1 & 0 \\
\hline 5 & $\begin{array}{l}\text { Defined criteria for } \\
\text { inclusion/exclusion }\end{array}$ & 0 & 0 & 0 & 0 & 0 & 0 & 0 & 0 & 0 \\
\hline 6 & $\begin{array}{c}\text { Drop out of final } \\
\text { analysis }<20 \%\end{array}$ & 2 & 2 & 2 & 2 & 2 & 2 & 2 & 2 & 2 \\
\hline 7 & $\begin{array}{c}\text { Specification of } \\
\text { population } \\
\text { characteristics }\end{array}$ & 1 & 0 & 1 & 1 & 1 & 0 & 1 & 1 & 0 \\
\hline 8 & $\begin{array}{c}\text { Data collection by } \\
\text { standardized } \\
\text { procedures }\end{array}$ & 0 & 0 & 0 & 0 & 0 & 1 & 1 & 2 & 0 \\
\hline 9 & $\begin{array}{c}\text { Methods for data } \\
\text { analysis }\end{array}$ & 0 & 0 & 0 & 0 & 1 & 0 & 0 & 0 & 0 \\
\hline 10 & $\begin{array}{c}\text { Reproducibility study } \\
\text { on description of } \\
\text { methods }\end{array}$ & 0 & 0 & 0 & 0 & 0 & 0 & 0 & 0 & 0 \\
\hline
\end{tabular}

No/Not reported $($ red $)=0$, Partially reported (orange) $=1$, Yes (green) $=2$, see legend in appendix B 


\subsection{Results}

\subsubsection{Study selection}

The search resulted in a total of 59 abstracts, including 2 additional abstracts found in the second search $[2,10]$. Another 4 abstracts were identified through other sources $[8,14,19,20]$, namely congress proceedings and reference scanning. In the PRISMA flow diagram, the numbers of records identified, included and excluded are displayed (Fig. 1 and Appendix B). The search on https://clinicaltrials.gov did not reveal any relevant studies. The identification and screening process resulted in a total of 25 full-text articles. These full-text articles were assessed for eligibility. Another 16 papers were excluded for several reasons summarized in Fig. 1. When identical cases were used, the paper with the shortest follow-up or earliest publication date was excluded $[17,19,21-23]$. Studies conducted in the same center but in different time windows with partially overlapping study populations were not considered redundant. Finally, 9 articles were included in this systematic review.

\subsubsection{Descriptive analysis}

2.4.2.1. Study type and design. All included articles were published between 2009 and 2020 .

The final 9 full-text articles included 6 case series $[1,3-5,14,15]$ and 3 case reports $[2,10,24]$. All of them were based on a retrospective study design, although 1 mentioned the use of prospectively collected data [3]. Gerlach et al. described ATx of fascia in 5 patients, but in 2 cases neither the type of graft nor the outcome was specified; therefore these 2 cases were not included in the review [1].
2.4.2.2. Patient demographics and centers. From 9 articles, a total of 74 patients were included (Table 1). Three articles concerning nonvascularized rectus fascia (NVRF) ATx $[3,4,14]$ and 3 articles about vascularized rectus fascia (VRF) ATx [5,15,24] overlapped with previous reports which were therefore not included [17,19,21-23]. In 63 patients NVRF ATx and in 11 patients VRF ATx was performed. Apart from the study by Amin et al. which did not mention the patient's age, children accounted for $40,5 \%$ of all patients $(n=53)$ with a NVRF ATx and $100 \%$ in case of a VRF ATx [14].

In the NVRF group, 51 were performed in association with an ITx (33 isolated ITx, 11 MvTx, 5 cLITx and 2 modified multivisceral transplantation (mMvTx)), 11 with a LTx and 1 with a kidney transplantation. In case of a VRF, 7 were performed with a LTx and 4 with a MvTx. Third party (from a different donor) NVRF was used in 16 cases $[2-4,10,14]$. For NVRF, apart from the first study where 7 cases of solely anterior fascia were reported [4], most cases were performed with a bilayer sheath for the NVRF including the peritoneal layer [2-4,14]. In case of VRF, only the posterior rectus fascia was used, although this was not clearly described in the poster by Reddy et al. [5,15].

\subsubsection{Surgical technique}

The included papers reported in detail the following surgical steps at the various centers: procurement, preservation, back-table preparation and transplantation.

\subsubsection{Non-vascularized Rectus Fascia Allotransplantation}

2.4.3.1.1. Donor procurement $(2-4,14,19)$. Acceptance criteria for donor organs at CUB were donor BMI $\leq 25$, donor height $<30 \mathrm{~cm}$ and donor weight $<30 \mathrm{~kg}$ greater than the recipient.

Several techniques for procurement of the rectus sheath have been

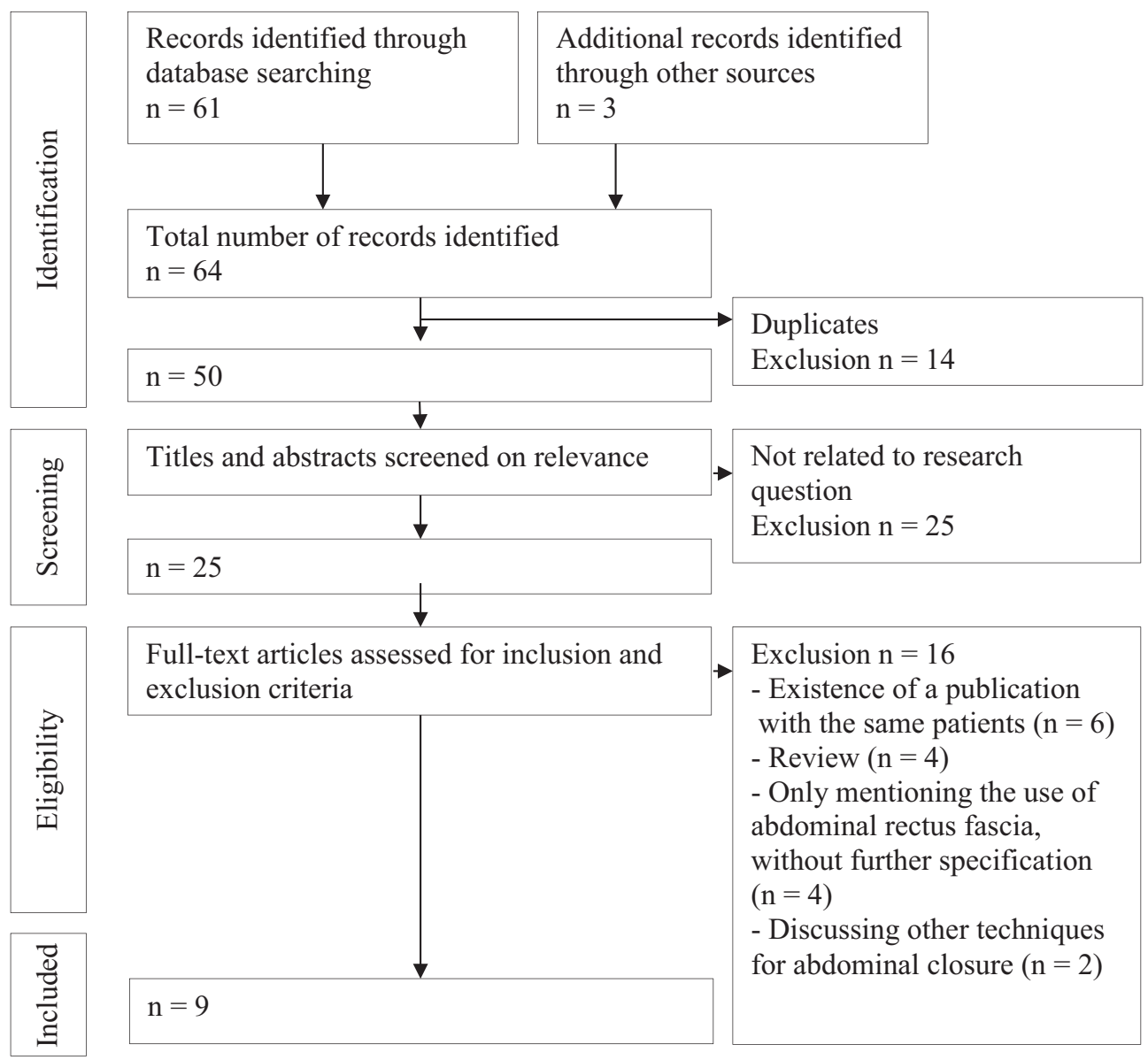

Fig. 1. PRISMA flow diagram. 
described. At the Hospital Universitario Fundación Favaloro and the Mount Sinai School of Medicine the technique for whole abdominal wall procurement was mimicked by performing a bilateral subcostal incision which extended to the lateral edge of the rectus muscle up to the pubis [7]. The complete abdominal wall is then reflected caudally. At the University of Miami and the King's Healthcare Partners Denmark Hill Site a cruciate abdominal incision or a thoracoabdominal incision, respectively, is performed down to the fascia. In both centers the skin and subcutaneous tissues are then mobilized as laterally as possible and the whole anterior fascia of the abdominal wall is exposed. At Cambridge University the skin and subcutaneous tissues are left attached to the fascia and rectus muscle.

Subsequently, the anterior and posterior rectus sheaths are incised at the semilunar line and down following the lateral edges up to the pectineal line. If only the anterior rectus sheath is used, it is dissected towards the linea alba and transected there [4]. If both anterior and posterior rectus sheaths are used, the rectus abdominis muscle with both layers of the rectus sheath is excised laterally following the superoinferior axis up to the pubis.

2.4.3.1.2. Preservation and back-table preparation $(2-4,14,19)$. At FF, MSSM, UM and CU, the graft is preserved in University of Wisconsin (UW) or Histidine-Tryptophan-Ketoglutarate solution [3] at $4{ }^{\circ} \mathrm{C}$ or on ice. At KHP the rectus muscle graft (with rectus sheath) is rolled in saline-soaked gauzes and kept in sterile cold preservation solution on ice.

If only the anterior rectus sheath is used, the orifices from perforating arteries are closed with 6-0 polypropylene sutures, according the technique described Farinelli et al. and Gondolesi et al. [3,4].

If the graft consists of the rectus muscle with the fascia attached, first a sharp longitudinal and bilateral opening of the lateral junction of the anterior and posterior fascia is performed, removing the lateral edges (fascia and the transverse, internal and external oblique muscles). Afterwards the rectus muscle is carefully removed towards the linea alba, as well as the remaining fat on the anterior fascia. After closing the small holes (perforating arteries) with polypropylene, the anterior and posterior sheath are loosely approximated by interrupted sutures. After the back-table preparation, the NVRF is preserved in a standard preservation solution at $4{ }^{\circ} \mathrm{C}$.

2.4.3.1.3. Timing of transplantation $(4,10)$. Gondolesi et al. describe a preservation time up to $26 \mathrm{~h}$ of the NVRF [4]. Justo et al report a mean cold ischemia time of $295 \mathrm{~min}$ (range $200 \mathrm{~min}-390 \mathrm{~min}$ ) and a mean warm ischemia time of $37.5 \mathrm{~min}$ (range $30 \mathrm{~min}-45 \mathrm{~min}$ ) for the solid organ transplant (SOT) and $44 \mathrm{~h}$ of cold ischemia time for the NVRF [10].

2.4.3.1.4. Recipient procedure $(1-4,14)$. After finishing the SOT, the fascial defect is assessed. Most articles recommended that the recipient abdominal wall has to be prepared with an extended dissection of the skin and subcutaneous tissue to ensure adequate skin flaps and obtain a "tension-free" closure. In some cases, lateral relaxing incisions are proposed to reduce the size of the abdominal defect. The donor rectus sheath is implanted and sutured inlay to the recipient's abdominal fascial edges with interrupted or continuous running 2-0 polypropylene (Prolene ${ }^{\circledR}$ ) sutures [3,4]. The use of 2 hemisheaths (anterior and posterior), split at the linea alba, instead of one large rectus sheath is also described in one case [3]. At FF, MSSM and UM a flat drain is placed between the rectus sheath and the skin when possible.

From the 63 patients who underwent NVRF ATx, skin closure was described in 23 patients, of which 14 were closed primarily $[4,10]$. Methods to manage secondary skin closure were wet to dry dressings ( $n$ $=3)$, vacuum negative-pressure wound therapy $(n=5)$, once in combination with a split thickness graft $(n=1)[1,2,4]$. Temporary coverage of the wound with paraffin gauzes was also described $(n=2)$ [2]. In the series by Gerlach et al. the 3 NVRF's were supported by a polyglactin mesh (Vicryl ${ }^{\circledR}$ ) as an underlay [1]. Despite graft edema in 2 of those patients, secondary fascial closure was achieved within 2 days [1]. Gondolesi et al. did not disclose any information about fascial closure rates [4]. In the series by Farinelli et al. and Amin et al. no details about skin nor fascial closure were given [3,14]. In the other articles primary fascial closure was described in 4 of the 7 NVRF patients $[1,10]$. Secondary fascial closure was achieved within 2 days to 2 months, with a median of 6 days [2,10].

2.4.3.2. Vascularized rectus fascia allotransplantation. The technique of VRF ATx involves the use of posterior rectus sheath above the umbilicus, which always stays attached to the liver graft by the falciform ligament. This ligament contains the hepatic falciform artery, providing blood flow to the posterior rectus sheath [17].

2.4.3.2.1. Donor procurement $(15,21)$. At DU, Ravindra et al first perform a dye perfusion study to confirm the presence of blood flow through the hepatic falciform artery.

Both groups from the UCMC and DU describe a midline incision through the skin and the subcutaneous fat up to the linea alba, followed by a lateral lift of the obtained tissue flaps (including the anterior fascia and rectus muscle). An edge of $2-4 \mathrm{~cm}$ of anterior rectus sheath flanking the linea alba is left attached. Finally, a bilateral incision at the semilunar line, subcostal incisions and an inferior incision at the arcuate line is made. The posterior rectus sheath stays attached to the donor liver via the falciform ligament. The other transplant organs are procured in a standard way.

2.4.3.2.2. Preservation and back-table preparation. Since the VRF graft is in continuity with the liver or multivisceral graft, the preservation is performed in a standard way, no additional dissection is needed and the peritoneal layer is preserved.

2.4.3.2.3. Timing of transplantation (15). Lee et al. report a mean cold ischemia time of $6.7 \mathrm{~h}$ (range: $4.8 \mathrm{~h}-7.9 \mathrm{~h}$ ) and a mean warm ischemia time (implantation time) of $35.8 \mathrm{~min}$ (range: $29 \mathrm{~min}-49 \mathrm{~min}$ ) [15].

2.4.3.2.4. Recipient procedure $(5,15,21)$. The liver or multivisceral graft is transplanted as per standard protocol with the posterior rectus sheath attached. Next, at UCMC the sheath is implanted as an inlay between the full thickness muscles of the recipient. At DU, the VRF is used as an underlay reinforcement in one case (with primary fascial closure) and as an inlay in the other cases, using polypropylene 4-0 [21].

Skin closure is described in 10 out of 11 VRF ATx, of whom 3 cases were closed primarily $[5,15]$. In 1 case secondary closure is achieved with the help of a skin graft [5]. In another case acellular dermis is used and in 3 cases an expanded polytetrafluoroethylene (Gore-tex ${ }^{\circledR}$ ) patch is used for temporary abdominal closure [5,15]. Primary fascial closure was possible in $50 \%$ of the VRF patients. Secondary fascial closure was achieved within 2 to 35 days [5,15,24].

\subsubsection{Immunology}

Little was described about the adaptation of the immunosuppressive medication in case of fascia transplantation. Since the intestinal graft is characterized by a stronger immunogenicity than for an isolated liver transplant, the immunosuppressive regimen in case of ITx is more profound. Justo et al. and Lee et al. described tacrolimus and steroids as the standard regimen, together with mycophenolate and daclizumab respectively $[10,15]$. Lee et al. was the only one who clearly states that the immunosuppression regimens were identical to the ones used in LTx without fascial ATx [15]. He also stated that at relaparotomy for second look surgery, biopsies taken from VRF in 4 patients showed no signs of rejection (range postoperative day 1-38) but gave few details. Farinelli et al., Gondolesi et al. and Justo et al. stated that there was no additional immunological risk associated to the use of third party fascial grafts $[4,10]$.

\subsubsection{Study outcomes}

Table 2 summarizes the study outcomes of the included patients. 


\subsubsection{Early wound morbidity}

The postoperative period was complicated by evisceration within 30 days in 1 ITx patient [3].

SSI's were described in 10 out of $61(16.4 \%)$ NVRF and 1 out of 11 (9.1\%) VRF patients. In the NVRF cases, 4 were superficial infections (of which 3 cases where the skin was not closed). SSI was not related to the type of SOT with a rate of $17 \%(n=6 / 35$ of the reported cases- for intestine-inclusive grafts and $31 \%$ ( $n=5 / 16$ of the reported cases) for an isolated liver transplant. In 6 cases a deep abdominal wall infection occurred, resulting in 1 partial and 4 complete graft removals [3,4]. Two of the NVRF's were replaced by a synthetic mesh and 1 by a third party NVRF. In the VRF cohort, 1 LTx case was complicated by multiple intraabdominal fluid collections, a biliary leak and a wound infection [15]. In this patient, primary skin closure had not yet been obtained at that time [15].

\subsubsection{NVRF and VRF unrelated complications and reoperations (Table 3)}

In 10 NVRF cases (5 ITx, 3 MvTx and 2 LTx), intra-abdominal collections or hematomas were reported, including 1 intra-abdominal bleeding $[3,10]$. For the VRF ATx, 1 intra-abdominal collection was described after LTx [15].

The number of reoperations per patient was mentioned in most papers. They were unrelated to the fascia transplant, apart from NVRF graft removals discussed in the SSI section. In 5 cases, the NVRF was removed at reoperation, kept in preservation fluid and re-implanted at the end of the re-operation [3]. For the VRF, Lee et al. performed 1 retransplantation of the liver and VRF at day 14 post-transplantation, due to hepatic artery thrombosis [15].

\subsubsection{Graft integration, rejection and herniation}

Later reoperations allowed some observations on the integration and evolution of the graft after transplantation. For the NVRF, Gondolesi et al. mentioned that, macroscopically, the graft was integrated in the abdominal wall (as part of scar tissue) with a maximum follow-up time of 42 months and Justo et al. confirmed this at 4 months post-transplant $[4,10]$. Gerlach et al. described the graft as part of the scar tissue without causing herniation (no timing described) [1]. Although adhesions were present intra-abdominally, none or only smooth adhesions were attached to the transplanted peritoneum. This was observed by Farinelli et al. at 2 to 42.5 months post-transplantation, by Cassar et al. after 1 year and by Amin et al. (no timing described) [2,3,14]. At those time points, manipulation, transection and suturing of the transplanted rectus sheath did not cause any complications $[2,3,14]$. No morphological change compatible with rejection of the NVRF ATx was seen in any patient.

For the VRF, biopsies of the fascia were taken in 3 patients between day 1 and day 38 post-transplant by Lee et al. [15]. They described a viable graft with excellent vascularity, bleeding at the fascial edges and arterial tones on Doppler ultrasound [15]. Furthermore these biopsies revealed no signs of rejection in any case [15].

In the included series of NVRF and VRF, the development of incisional or ventral hernias during the follow-up period was not mentioned or not clearly described for any of the patients (Table 2) other than the one patient who required removal of the NVRF [4].

Graft loss occurred in 5 NVRF patients and in 1 VRF patient, caused by deep abdominal wall infections in 4 cases and retransplantation of the SOT and VRF allotransplant (AT) due to hepatic artery thrombosis in 1 case.

\subsubsection{Survival and cause of death}

The first NVRF study reported 7 deaths in the postoperative period [4]. The causes of death were all fascial graft unrelated: sepsis (woundunrelated) $(n=4)$, autoimmune hemolysis $(n=1)$ and post-transplant lymphoproliferative disease $(n=2)$. In later articles the mortality rate dropped to zero $[1,2,10]$.

In the VRF group, 2 patients died, both unrelated to the fascial graft.
One was due to aspergillosis sepsis, the other cause of death was not mentioned, but was not graft-related $[5,15]$.

\subsubsection{Quality appraisal}

None of the reviewed articles fulfill more than 4 of the 10 selected methodological quality criteria. In a descending order of prevalence, the following elements are satisfactorily addressed (as indicated in Table 4 by a score of 2 and green cell coloring): drop out $<20 \%$ (all 9 articles), definition of surgical technique ( 6 articles) $[2-5,10,14,15]$, description of time period ( 4 articles) $[1,3,4,15]$, description of sampling design (3 articles) $[1,3,5]$, data collection by standardized procedures ( 1 article) [15]. All other criteria are either partially addressed (score 1, orange) or not reported (score 0, red).

\section{Discussion}

In 2003, Levi et al. were the first to introduce the abdominal wall transplantation, a vascular composite tissue allograft with the potential advantage of early rejection detection via a skin allograft $[6,7,25]$.

The less complex or less time-consuming NVRF and VRF ATx have successfully been used in transplant surgery since their first description by Gondolesi et al. in 2009 and Agarwal et al. in 2010 respectively. The main purpose of these techniques is (primary) closure of extensive abdominal wall defects, mainly after ITx, MvTx or LTx $[4,17]$ and thereby avoiding an "open abdomen", which severely impacts the morbidity and mortality in this vulnerable transplant population. This review summarizes the experience of 63 NVRF ATx and 12 VRF ATx in 74 transplant patients $[1-5,10,14,15,24]$.

\subsection{Technique}

The main anatomical difference between the two rectus fascia ATx techniques is the presence of vascularization through the falciform ligament in the VRF ATx. This means that for VRF ATx, inclusion of the liver in the graft is mandatory whereas the NVRF ATx can be used in all types of solid organ transplantation. Furthermore, the NVRF ATx can be procured from a different, third party donor [2-4,10,14] and can be used for larger defects [2]. The NVRF AT consists of the anterior fascia with or without the posterior fascia (sometimes with a rim of anterior fascia at the linea alba). In case of VRF Tx, only the use of the posterior rectus sheath has been reported.

The addition of the RF ATx to the SOT procedure prolongs the procurement and operative time but is less complex and time-consuming in comparison to abdominal wall transplantation or autologous tissue transfer. Since the VRF relies on the arterial vascularization within the falciform ligament, this type of graft is more vulnerable than a NVRF and patency should be assessed prior to procurement.

Although preservation is currently on ice in classic preservation solution, and has been shown safe up to $26 \mathrm{~h}$, prolonging the preservation time or mode (e.g. deepfreezing) of a NVRF graft, might open up the window towards other indications in a non-SOT setting. Further research on this topic is awaited.

\subsection{Outcome}

Mortality was unrelated to the transplantation of the rectus fascia in both types, 7 (30.4\%) in case of NVRF and $2(18.2 \%)$ in case of VRF ATx. Since the VRF is attached to the liver and vascularized through the hepatic artery, thrombosis is the most feared complication. In case of thrombosis (e.g. of the hepatic artery), the liver graft and thus the attached fascia are lost and need to be replaced by a new liver-VRF transplantation $[2,15]$.

Abdominal closure by RF ATx was achieved in all cases. In the studies that described fascial closure, primary closure accounted for $47 \%$ and secondary closure for 53\% [1,2,5,10,15,24]. Primary skin closure was achieved in $51.5 \%$ of all cases that reported details about skin closure, 
counting for $60.9 \%$ of the NVRF AT and $30.0 \%$ of the VRF AT patients (Table 2).

Four out of 13 patients (30.8\%) in whom the skin could not be closed primarily developed an SSI. However, secondary skin closure could be achieved in all cases without any graft related complications.

In 2009, Gondolesi et al. were the first to perform a NVRF ATx [4]. In the subsequent study, 7 out of the 16 patients developed SSI's (43.8\%). Since this publication it was thought that the NVRF ATx had a higher infection risk than its vascularized variant. It was hypothesized that the blood flow through the vascularized fascia improves the viability and the immune response against infections. In addition, the administration of systemic antibiotic treatment and the wound healing could be more efficient through the native vascularization of the VRF AT [4,15,21]. The occurrence rate of SSI's remained higher after NVRF ATx than after VRF ATx (9.1\%). Nevertheless, this risk has decreased from $43.8 \%$ to a range from 0 to $15.8 \%$ in later NVRF ATx publications [1-3,10].

It should be noted that transplant patients (particularly ITx and MvTx recipients) are already more prone to infections, due to their immunosuppressive status, prolonged hospitalization and malnutrition [4]. The presence of chronic contamination (wound infections, enterocutaneous fistulae and/or ostomies) increases the risk of SSI's even more. Although intestine-related grafts depend on higher levels of immunosuppression than LTx, SSI did not relate to the type of graft in this review. More data on the incidence of SSI's is warranted.

We recommend that in future studies results should be analyzed in the context of LTx versus ITx separately. With ITx one should take into account the higher risk of contamination, the potential need for a stoma and the higher immunosuppressive requirements. These are important factors when analyzing post-operative complications, in particular SSI's and hernia formation. The included articles don't allow us to differentiate for most outcomes between the two types of SOT. Although outcome in general was very satisfying.

The NVRF AT has proven to integrate well into the hosts abdominal wall and allows post-transplant manipulation (re-elevation and re-inset) for reoperations $[1-4,10]$, also when only the anterior NVRF AT was used [4]. However, data on the latter are limited. We assume that for the NVRF AT the presence of the peritoneum to the posterior fascia might be the reason why it has no tendency to form adhesions. At re-exploration it has been described in 2 patients that the VRF graft was well revascularized in the immediate (post-operative day 0,2 and 3) and late postoperative periods (post-operative day 31 and 38) [15]. It is still unknown whether or not revascularization occurs and if this could also be the case for NVRF grafts. We hypothesize that the surrounding tissues provoke neovascularization. The role of the different surrounding tissues in this (peritoneum, subcutaneous tissues, and others...) has to be studied. Nevertheless, it has been noticed that the integration of the posterior layer of the NVRF graft resulted in less development of intraabdominal adhesions to the RF.

The rate of RF ATx graft loss was $12.8 \%$, either caused by severe infections or by non-related causes. For the future we suggest to collect more information on timing of the NVRF and VRF integration into the recipient tissue, and if possible, to combine it with standard imaging of duplex ultrasound or computed tomography.

\subsection{Immunology}

Fascia is considered poorly immunogenic due to its constitution and, in case of the NVRF AT, its avascularity [2,4]. Therefore, it has been hypothesized that ABO- and human leukocyte antigen-matching is not mandatory. Third party (e.g. from a different donor) NVRF were successfully used in 16 cases [2-4,10,14]. Cassar et al. were the only ones using an ABO-matched third party NVRF out of precaution [2].

An issue to be taken into account is the peritoneal layer attached to the posterior RF [2]. In contrast to fascia, the peritoneum is cell-rich and assumed to be an important immunogenic trigger for rejection although this does not seem to be a clinically relevant problem in this population under immunosuppression [1-4,10,14].

Life-long immunosuppression after organ transplantation is mandatory. Even in case of a third party NVRF, Farinelli et al., Gondolesi et al. and Justo et al. state that there is no immunological disadvantage associated $(n=16)[3,4,10]$.

Within the included articles no rejection of the RF ATx was documented while SOT rejection occurred in 3 patients (4.1\%) [3]. This seems to confirm that in this population of already immunosuppressed patients, there does not seem be an additional immunogenicity related to the fascial component of the graft; and probably no need for additional or modified immunosuppression.

The seemingly low additional immunogenicity of the RF ATX could lead to the application of this technique in low or even nonimmunosuppressed patients with complex abdominal defects who are not treatable by more conventional techniques.

To investigate these immunological and rejection issues in more detail and to evaluate the alloimmune response elicited by the peritoneum and/or the rectus fascia, a high-quality allogeneic animal model is needed.

\subsection{Hernia occurrence}

Adequate abdominal wall closure and strong tissue integration is crucial to prevent incisional hernia occurrence. Hernia formation is an important prognostic factor, especially for long-term outcomes such as quality of life, patient satisfaction, rehospitalizations and reoperations [26]. Although not clearly explained, Gondolesi et al. described that one patient developed a hernia after the NVRF was removed [4]. Additionally the early post-operative period of 1 patient was complicated by evisceration [3]. This required a re-operation, but no re-transplantation of the NVRF.

The incidence of long-term herniation or bulging is scarcely reported in the included articles. It is intriguing that a technique of inlay graft placement (without overlap with the native tissue) which has been largely abandoned in abdominal wall mesh reconstructions by general surgeons, seems to function properly in this challenging group of complex and immunocompromised patients.

Further investigations on neovascularization and formation of mature collagen in an allogeneic animal model are therefore needed. In addition, high quality clinical and radiological data through prospective transplant registries with a follow-up of at least one year post-transplant could provide better data on this important patient outcome parameter.

\subsection{Study quality}

Due to lack of standardized data reporting, the information within this systematic review remains incomplete. In the quality appraisal the overall score on reproducibility was very low. None of the included articles had a prospective design. Lee et al. were the only ones who had a relatively standardized data collection [15]. The included articles contain 3 posters of which the data are only briefly described [5,14,24]. The incidence of SSI's is not reported by default [2,3,24], nor the detailed postoperative course $[14,24]$ or the immunological implications. There were only two articles, that discuss warm ischemia and operative time $[10,15]$. Furthermore, it should be mentioned that VRF ATx has only been performed in children.

Another issue is the publication of patients who have already been published in a previous article. The exact amount of 'overlapping' patients was not explicitly mentioned, but we suspect overlap with previous reports in at least 4 of the included publications [3-5,23].

\section{Conclusion}

Vascularized and non-vascularized rectus fascia allotransplantation are promising techniques for complex abdominal wall reconstruction after solid organ transplantation. Both have proven to achieve 
abdominal wall closure after transplantation. Although these two techniques seem to be feasible, safe and effective, more detailed and more long-term results are lacking, specifically on the occurrence of SSI's, rejection and herniation.

Hence, we want to emphasize the importance of prospective data collection, such as the outcome parameters discussed in this systematic review.

Furthermore, preclinical research with a high-quality allogeneic animal model could help to answer questions on immunological aspects and graft integration on the short -and long-term by clinical, biomechanical, histopathological and immunohistochemical analysis. This will provide the necessary information before applying this technique to a population of patients with complex abdominal wall defects (outside the setting of solid organ transplantation) who would not be amenable to more conventional techniques.

Unrelated disclosures

Nele Van De Winkel is supported a doctoral grant from the University Hospitals Leuven (KOOR-UZ Leuven) and reports personal fees from Medtronic.

Jacques Pirenne is supported by a KU Leuven University Chair funded by IGL.
Laurens J. Ceulemans is supported by a KU Leuven University Chair funded by Medtronic and a post-doctoral grant from the University Hospitals Leuven (KOOR-UZ Leuven).

Marc Miserez reports grants from Duomed, grants from FEG, grants and personal fees from Medtronic, personal fees from Bard, personal fees from Lifebond, personal fees from Springer.

\section{Funding}

This research did not receive any grant from funding agencies in the public, commercial or not-for-profit sectors.

\section{Declaration of Competing Interest}

The authors of this manuscript have no conflicts of interest to disclose in relation to this manuscript.

\section{Acknowledgement}

The authors of this manuscript have no acknowledgements to report in relation to this manuscript.

Appendix A. Abbreviations

\begin{tabular}{lll}
\hline 1 & PRISMA & Preferred Reporting Items for Systematic reviews and Meta-Analyses \\
2 & ITx & intestinal transplantation \\
3 & cLITx & combined liver intestinal transplantation \\
4 & LTx & multivisceral transplantation \\
5 & MvTx & non-vascularized rectus fascia \\
6 & NVRF & allotransplantation \\
7 & ATX & vascularized rectus fascia \\
8 & VRF & modified multivisceral transplantation \\
9 & mMvTx & kidney transplantation \\
10 & KTx & solid organ transplant\#\#\# \\
11 & SOT & Docede Octubre University Hospital \\
12 & DO & King's Healthcare Partners Denmark Hill Site London \\
13 & KHP & Hospital Universitario Fundación Favaloro \\
14 & FF & Charité - Universitätsmedizin Berlin \\
15 & CUB & University of Miami \\
16 & UM & Mount Sinai School of Medicine \\
17 & MSSM & Cambridge University Addenbrooke's Hospital \\
18 & CU & University of Chicago Medical Center \\
19 & UCMC & Duke University \\
20 & DU & not mentioned \\
21 & NM & female \\
22 & F & male \\
23 & M & University of Wisconsin \\
24 & UW & Surgical site infections \\
25 & SSI & allotransplant \\
26 & AT & vacuum negative-pressure wound therapy \\
27 & VAC & Split-thickness skin graft \\
28 & STSG & skin graft \\
29 & SG & rectus fascia \\
30 & RF & \\
\hline
\end{tabular}

\section{Appendix B. Supplementary data}

Supplementary data to this article can be found online at https://doi.org/10.1016/j.trre.2021.100634.

\section{References}

[1] Gerlach UA, Pascher A. Technical advances for abdominal wall closure after intestinal and multivisceral transplantation. Curr Opin Organ Transplant 2012;17: 258-67.

[2] Cassar N, Cortes-Cerisuelo M, Bambridge C, Ali A, Heaton N, Vilca-Melendez H. The difficult abdominal closure after paediatric intestinal transplantation: use of abdominal rectus muscle fascia and literature review. Pediatr Transplant 2019 Aug;23:e13473.
[3] Farinelli PA, Rubio JS, Padín JM, Rumbo C, Solar H, Ramisch D, et al. Use of nonvascularized abdominal rectus fascia after liver, small bowel, and multiorgan transplantation: long-term follow-up of a single-center series. Transplant Proc 2017;49:1810-4.

[4] Gondolesi G, Selvaggi G, Tzakis A, Rodríguez-Laiz G, González-Campaña A, Fauda M, et al. Use of the abdominal rectus fascia as a nonvascularized allograft for abdominal wall closure after liver, intestinal, and multivisceral transplantation. Transpl Int 2009;87:1884-8. Available from: http://content.wkhealth.com/linkba ck/openurl?sid=WKPTLP:landingpage $\&$ an $=00007890-200906270-00020$. 
[5] Reddy J, Rege A, Vikraman D, Collins B, Brennan T, Knechtle S, et al. Use of Enbloc vascularized rectus sheath allograft to achieve abdominal closure in pediatric liver and multivisceral transplantation. Am J Transplant [Internet] 2016;16:764-5. Available from: http://www.embase.com/search/results? subaction=viewrecord \&from=export\&id=L611700183\%5Cnhttps://doi.org/10.1111/ajt.13898\%5Cnh ttp://sfxhosted.exlibrisgroup.com/galway?sid=EMBASE\&issn=16006143\&id=doi $: 10.1111 \% 2$ Fajt.13898\&atitle $=$ Use + of + En-bloc + vascularized + .

[6] Giele H, Vaidya A, Reddy S, Vrakas G, Friend P. Current state of abdominal wall transplantation. Curr Opin Organ Transplant [Internet] 2016;21:159-64. Available from: http://content.wkhealth.com/linkback/openurl?sid=WKPTLP:landingpage \&an $=00075200-201604000-00014$

[7] Levi DM, Tzakis AG, Kato T, Madariaga J, Mittal NK, Nery J, et al. Transplantation of the abdominal wall. Lancet. 2003;361:2173-6.

[8] David AI, Gouvea ES, Batista FR, de Barros PHF, Martini Filho D, Arias V, et al. Analysis of transplant rejection in rabbits aponeurosis. Einstein (Sao Paulo)

[Internet] 2012;10:302-5. Available from: https://www.ncbi.nlm.nih.gov/pubmed $/$ ?term $=$ Analysis + of + transplant + rejection + in + rabbits + aponeurosis.

[9] Mangus RS, Kubal CA, Tector AJ, Fridell JA, Klingler K, Vianna RM. Closure of the abdominal wall with acellular dermal allograft in intestinal transplantation. Am J Transplant 2012 Dec;12:S55-9.

[10] Justo I, Marcacuzco A, Caso O, Manrique A, Calvo J, Garcia-Sesma A, et al. Use of nonvascularized fascia in liver transplantation. Transplant Proc 2020 Mar;52(5): $1468-71$.

[11] Carlsen BT, Farmer DG, Busuttil RW, Miller TA, Rudkin GH. Incidence and Management of Abdominal Wall Defects after intestinal and multivisceral transplantation. Plast Reconstr Surg 2007;119:1247-55.

[12] Cloonan MR, Fortina CA, Mercer DF, Vargas LM, Grant WJ, Langnas AN, et al. Failure of abdominal wall closure after intestinal transplantation: identifying highrisk recipients. Clin Transpl 2019 Nov 1;33(11).

[13] Ceulemans LJ, Deferm NP, Miserez M, Maione F, Monbaliu D, Pirenne J. The role of osmotic self-inflatable tissue expanders in intestinal transplant candidates. Transplant Rev 2016;30:212-7.

[14] Amin I, Russell N, Sharkey L, Butler A. Use of avascular rectus abdominis fascia for abdominal closure in transplantation. Abstr 19th Congr Eur Soc Organ Transplant 2019;32:72.
[15] Lee JC, Olaitan OK, Lopez-Soler R, Renz JF, Millis JM, Gottlieb LJ. Expanding the envelope: the posterior rectus sheath-liver vascular composite allotransplant. Plast Reconstr Surg [Internet] 2013;131:209e-18e. Available from: http://www.ncbi. nlm.nih.gov/pubmed/23358016.

[17] Agarwal S, Dorafshar AH, Harland RC, Millis JM, Gottlieb LJ. Liver and vascularized posterior rectus sheath fascia composite tissue allotransplantation. Am J Transplant 2010;10:2712-6.

[18] Ceulemans LJ, Lomme C, Pirenne J, De Geest S. Systematic literature review on self-reported quality of life in adult intestinal transplantation. Transplant Rev 2016;30:109-18.

[19] Butler A, Russell N, Amin I, Sharkey L. Use of avascular rectus abdominus fascia for abdominal closure in transplantation. Transplantation 2017;101.

[20] Loinaz C, Talayero P, Grau M, Naranjo L, Del Pozo P, Cabrera O, et al. Immune response in an experimental model of pig to rabbit abdominal fascia transplantation. Transplantation. 2019;103:146.

[21] Ravindra KV, Martin AE, Vikraman DS, Brennan TV, Collins BH, Rege AS, et al. Use of vascularized posterior rectus sheath allograft in pediatric multivisceral transplantation - report of two cases. Am J Transplant 2012;12:2242-6.

[22] Gondolesi G, Gondolesi G, Farinelli P, Ramisch D, Romero P, Rumbo C, et al. Use of abdominal rectus fascia after intestinal and multiorgan transplantation in a single center, long-term follow-up. Transplantation. 2014;98:217.

[23] Ravindra KV, Hollenbeck S, Erdmann D, Turley R, Sudan DL. Use of vascularized rectus sheath as a composite tissue allograft in multivisceral bowel transplantation to reconstruct abdominal wall. Am J Transplant 2011;11:87-8.

[24] Ravindra KV, Hollenbeck S, Martin A, Vikraman D, Brennan T, Erdman D, et al. Use of rectus sheath as a vascularized composite tissue allograft in multivisceral transplantation. Am J Transplant 2011;11:281.

[25] Barnes J, Issa F, Vrakas G, Friend P, Giele H. The abdominal wall transplant as a sentinel skin graft. Curr Opin Organ Transplant [Internet] 2016;21:536-40. Available from: http://content.wkhealth.com/linkback/openurl?sid=WKPTLP:la ndingpage \&an $=00075200-201610000-00014$.

[26] Licari L, Guercio G, Campanella S, Scerrino G, Bonventre S, Tutino R, et al. Clinical and functional outcome after abdominal wall incisional hernia repair: evaluation of quality-of-life improvement and comparison of assessment scales. World J Surg 2019;43(8):1914-20. 